\title{
A Decision-Making Model Using Machine Learning for Improving Dispatching Efficiency in Chengdu Shuangliu Airport
}

\author{
Yingmiao Qian, ${ }^{1,2}$ Shuhang Chen, ${ }^{3}$ Jianchang Li, ${ }^{4}$ Qinxin Ren, ${ }^{5}$ Jinfu Zhu, ${ }^{3}$ Ruijia Yuan, \\ and $\mathrm{Hao} \mathrm{Su}^{5}$ \\ ${ }^{1}$ School of Management Science and Engineering, Anhui University of Finance and Economics, Bengbu 233030, China \\ ${ }^{2}$ School of Management, Hefei University of Technology, Hefei 230009, China \\ ${ }^{3}$ Design School, Xi'an Jiaotong-Liverpool University, Suzhou, Jiangsu 215123, China \\ ${ }^{4}$ School of Science, Xi'an Jiaotong-Liverpool University, Suzhou, Jiangsu 215123, China \\ ${ }^{5}$ School of Advanced Technology, Xi'an Jiaotong-Liverpool University, Suzhou, Jiangsu 215123, China \\ ${ }^{6}$ School of Civil Engineering, Central South University, Changsha 410075, China \\ Correspondence should be addressed to Ruijia Yuan; rj.yuan@csu.edu.cn
}

Received 26 October 2020; Revised 21 November 2020; Accepted 3 December 2020; Published 16 December 2020

Academic Editor: M. Irfan Uddin

Copyright (C) 2020 Yingmiao Qian et al. This is an open access article distributed under the Creative Commons Attribution License, which permits unrestricted use, distribution, and reproduction in any medium, provided the original work is properly cited.

Due to the increasing number of people traveling by air, the passenger flow at the airport is increasing, and the problem of passenger drop-off and pickup has a huge impact on urban traffic. The difficulty of taking a taxi at the airport is still a hot issue in the society. Aiming at the problem of optimizing the allocation of taxi resource, this paper is based on the cost-benefit analysis method to determine the factors that affect the taxi driver's decision-making. The mathematical methods such as function equation, BP neural network algorithm, and queuing theory were used to establish a complete decision-making model for taxi drivers and an optimization model of dispatching efficiency at the airport. A conclusion has been drawn that the allocation of airport taxi resource should be arranged closely related to drivers' revenue and the layout of airport line.

\section{Introduction}

With the rapid development of the transportation network, aircraft has become one of the most important means of transportation for people [1]. After getting off the plane, most passengers go to the destination in the urban area (or the surrounding area) and taxi has become one of the main means of transportation [2]. As a result, taxi dispatching at the airport has become a research issue, for improving the efficiency of picking up passengers at the departure. As reported in several contributions, improvement of transportation conditions in airport can contribute to the economy development $[3,4]$. Therefore, taxi dispatching efficiency (TDE) has great significance for the development of airport economic zone.
Cost-effective analysis (CBA) is an effective method to evaluate the potential economic impact of investment choices $[5,6]$. The managers should collect information related to uncertain factors in the decision-making process so that they can make the best choice [7]. By taking the multiple impacts of different choices into consideration under the background of difficult budgetary arbitrations, the CBA method makes decision-making process a quantitative analysis, providing the decision-makers with prior strategy. In 2009, Damart and Roy utilized the CBA method to evaluate the decision-making context of transport infrastructure in France and found that rationalization of public resource use and stakeholder acceptance of the choices are two elements that affects the improvement of transport infrastructure in France [6]. In 2016, Burgain et al. applied 
CBA to congested airport departure operations for ameliorating the departure operations in airport [8]. Abovementioned research used CBA for analyzing and improving the decision-making problems but there was limited research on the decision-making strategy for taxi drivers at the airport.

Error back propagation (BP) neural network is one kind of neural network algorithms that can be applied in research field, such as intelligent control, combinatorial optimization, and image processing [9]. Since the late 20th century, BP network has been widely used in the traffic engineering field. In 2002, Mo and Su predicted the passenger volume on realtime transit by using the neural network [10]. After that, $\mathrm{He}$ et al. applied the backpropagation (BP) network to forecast the total volume in the waterway [11]. In 2013, Yong and Tao analyzed the demand characteristics of passenger transportation by BP network algorism [12]. Zheng et al. made prediction and design on the road transportation network planning with the prediction model constructed under BP neural network in early 2018 [13].

HRRN is one of the most commonly used scheduling methods in modern computer-operating systems [14], which can be used to improve the operating efficiency of the system and is an excellent scheduling algorithm. In 2003, Liu et al. applied the HRRN method to the bus arbitration [15]. Surendra Varma used HRRN strategy for analyzing prioritybased systems considering burst time, arrival time, and priority [14] in 2013. All the aforementioned literature effectively used BP network to predict the dynamic transportation, and HRRN to analyze the priority in the dispatching system in airport. However, there was limited focus on the interaction between the transportation and passengers.

To improve the efficiency rationally, by gaining the experience from Damart's research in France, two sides, both the taxi driver and the management department in Shuangliu airport will be taken into consideration. The optimization model of dispatching efficiency is constructed by firstly constructing the decision-making model for taxi drivers in Shuangliu airport for that dynamic movement of taxis has been taken into account. Secondly, the dispatching model can be established by considering the departure plan of Shuangliu airport. Some precipitate changes would make it difficult to ensure the validity of the dispatching model. Thus, it is necessary to consider and control the related changes [16]. To improve the sensitivity of the dispatching model, different weather condition and holiday influence on the decision-making model and dispatching model have been discussed. A comprehensive risk evaluation approach which includes a risk index framework and related quantitative ways is also important [17]. However, this approach is not necessary since risk evaluation is not the focus of this research. Eventually, the final model has been constructed with a good sensitivity.

\section{Materials and Methods}

Taxi drivers who drop off passengers at the airport will face two options:
Option 1: go to the arrivals area and queue to get the passengers to return to the city. Taxi drivers must go to the designated parking lot to wait in line due to the "first-come-first-served" basis. The length of the waiting time depends on the number of taxis and the number of passengers in the queue, which requires a certain cost of time.

Option 2: return directly to the city to get the passengers in the city. Taxi drivers pay no-load fees and may lose potential revenue from the airport.

The number of flights arriving in a certain period of time and the number of vehicles already in the parking lot are certain information that the drivers can observe. Usually, the drivers' decision is related to his personal experience, such as the number of flights arriving in a certain time period and the number of possible passengers [18]. If passengers want to take a taxi after getting off the plane, they have to queue up at the designated parking lot and get a ride in order. The airport taxi management staff is responsible to quantificationally release taxis into the parking lot and arrange a certain number of passengers to board.

In order to establish a reasonable decision-making model for taxi drivers, this paper uses cost-benefit analysis to carefully differentiate the factors having impact on the profits of waiting at airport and the profits of returning to the city. For the benefits of drivers waiting at the airport, both the waiting cost of the drivers and the revenue gained from pulling passengers back to the city need to be considered. Among them, the waiting cost of drivers is predicted by the number of flights to port, passenger flow number, assumed traffic flow, and other variables such as weather condition [19]. As for the benefits of drivers returning to the urban area to take passengers, this paper mainly considers the cost of empty running on the way to the urban area and the revenue from carrying passengers in the urban area. Revenue from passengers and cost of empty running are affected by the distance from the airport to the urban area and the distance of different destinations in the urban area [20,21]. Normal distribution of the distance between the airport and the urban area and the distance within the urban area is modified by real-time map, so as to obtain the decisionmaking model for the drivers who choose to carry passengers in the city area. Finally, by comparing the profit of the driver waiting at the airport with the profit of the driver going to the city to pick up passengers, the best decision of the driver is given. The flowchart of the whole cost-benefit analysis is shown in Figure 1:

\subsection{Construction of Decision-Making Model for Taxi Drivers}

\subsubsection{Assumptions}

(1) The behavior of the taxi driver is in line with the "rational agent" assumption, which means that the taxi driver always chooses the decision plan with the greatest expected economic profits.

(2) When studying the situation of taxis picking up passengers at the airport, it is assumed that the 


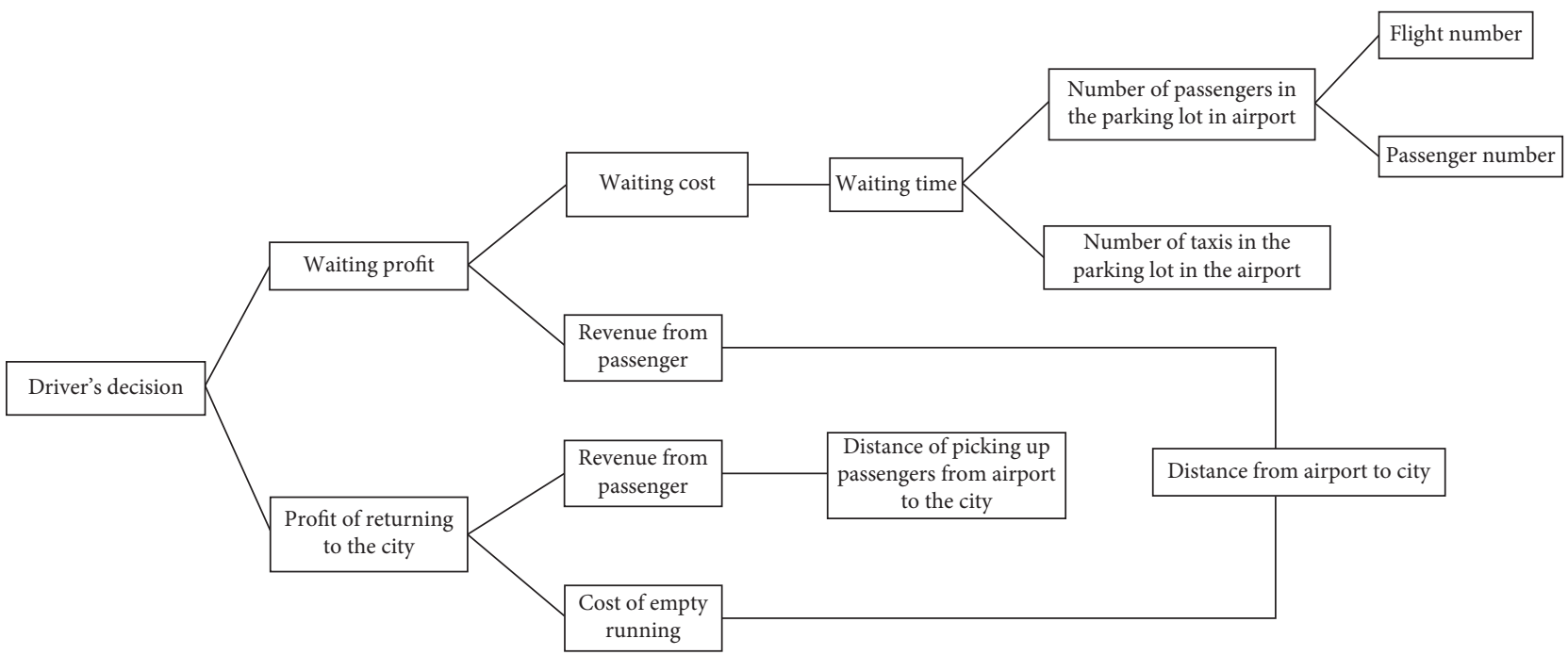

Figure 1: Cost-benefit analysis chart.

number of passengers is always bigger than 1, which means that the taxis drivers are always able to receive passengers at the airport.

(3) When passengers take a taxi at the airport, it is assumed that the traffic volume is always equal to or greater than 0 , which means that the passengers may get the taxi in the parking lot without wait, or they may need to wait for some time before getting on a taxi.

(4) The one-way income obtained by taxi drivers waiting at the airport is greater than the one-way income obtained by carrying passengers in urban area.

(5) The revenue and cost of taxi drivers to take passengers are only related to the carrying distance, fare, fuel cost, which have no relationship with the location.

(6) The distance from the airport to the city and within the city area is of normal distribution.

(7) The charge of taxi service is the same during the day and night.

(8) All taxis are refueled with gasoline No. 92 (a fuel used in China).

2.1.2. Notation Explanation. Explanation for notations are presented in Table 1.

\subsection{Establishment of Decision-Making Model for Taxi Drivers.} First of all, this paper considers that the main factors affecting the passenger flow of a parking lot at an airport in China are: (1) passenger flow at the airport; (2) flight number at the airport; (3) weather condition; (4) impact of holidays such as Saturday and Sunday. Because the impact of weather condition and vacation are hard to be quantified, the first two factors are mainly considered.
2.2.1. Number of Passengers in the Parking Lot. According to the influencing factors of the parking lot passenger volume: (1) the passenger flow at the airport; (2) the number of arrivals at the airport and the function relationship between the parking lot passenger volume and the influencing factors have been obtained using the BP neural network:

$$
N_{C}=f_{\text {network }}\left(x_{i}\right)
$$

where $x_{i}$ represents the influencing factor of the passenger volume of the parking lot.

2.2.2. Passengers' Waiting Time in the Parking Lot. Consider the influencing factors of taxi driver waiting time:

(1) The number of passengers in the parking lot

(2) The parking lot traffic flow

A mathematical relationship between passenger waiting time and passenger volume in the parking lot can be expressed by

$$
t_{C}=\left(N_{C}-1\right) t_{0}+N_{C} \cdot t_{1}
$$

where $N_{C}$ is the number of passengers waiting in line in the parking lot, $t_{0}$ is the time gap between when the last taxi has just been picked up and the next taxi in the parking lot is taken, and $t_{1}$ is the passengers' boarding time.

2.2.3. Taxi Driver's Waiting Time in the Parking Lot. Considering the assumption that the taxi drivers are always able to receive passengers in the parking lot, the mathematical relationship between the taxi drivers' waiting time and the passengers' waiting time can be expressed as follows [22]: 


$$
\begin{aligned}
\left(t_{C}\right)^{n_{1}}\left(t_{D}\right)^{n_{2}} & =K, 0 \leq n_{1} \leq 1,0 \leq n_{2} \leq 1, \\
K & =\frac{1}{A}\left(N_{C}\right)^{1 / 2-n_{1}}\left(N_{D}\right)^{1 / 2-n_{2}}, \\
A & =a_{0}(\phi)^{n_{0}},
\end{aligned}
$$

where $a_{0}, n_{0}, n_{1}, n_{2}$ are the coefficients affected by the location of the airport, $\phi$ is the coefficient affected by the size of the airport, and $N_{C}$ and $N_{D}$ represent the number of passengers and taxis in the airport parking lot at a certain moment. When the airport is determined, the values of $a_{0}, n_{0}, n_{1}, n_{2}, \phi$ and the number of passengers and drivers at the airport parking lot at a certain time can be determined, so that the taxi drivers' waiting time in the parking lot can be calculated as

$$
t_{D}=\left(\frac{\left(N_{C}\right)^{(1 / 2)-n_{1}}\left(N_{D}\right)^{(1 / 2)-n_{2}}}{a_{0}(\phi)^{n_{0}} \cdot\left(t_{C}\right)^{n_{1}}}\right)^{1 / n_{2}} .
$$

2.2.4. Taxi Drivers' Waiting Cost. Because the taxi driver's waiting cost is equal to the income of the taxi driver returning to the urban area directly in the same time [23], the relationship between the cost of waiting time and waiting time can be expressed as

$$
C_{\text {wait }}=E \cdot t_{D}
$$

where $E$ is the expected earnings per hour when the driver is waiting and $t_{D}$ is the waiting time of the driver in the parking lot.

2.2.5. Taxi Drivers' Profit of Waiting in the Parking Lot. Calculating the driver's income from waiting in the parking lot minus the waiting cost, the waiting income of the driver at the airport parking lot can be expressed as

$$
R_{\text {wait }}=\left(D_{D}-d\right) \cdot f+F-D_{D} \cdot f_{o}-E \cdot t_{D},
$$

where $D_{D}$ is the distance between the airport and the city, $d$ is the mileage of taxi starting price, $f$ is the fare per kilometre after the mileage exceeds $d, f_{\mathrm{o}}$ is the fuel cost per kilometre of taxi, and $F$ is the starting price.

2.2.6. Taxi Drivers' Profit of Directly Returning to the City. By calculating the driver's income from carrying passengers in the urban area minus the empty running cost of driving to the urban area, the corresponding profit can be derived. Considering the different distance, when the distance is less than $d$, the profit can be expressed as

$$
R_{\mathrm{go}}=k\left(F-d_{D} \cdot f_{\mathrm{o}}\right)-D_{D} \cdot f_{\mathrm{o}} .
$$

When the distance is greater than $d$, the profit can be expressed as

$$
R_{\mathrm{go}}=k\left(\left(d_{D}-d\right) \cdot f+F-d_{D} \cdot f_{\mathrm{o}}\right)-D_{D} \cdot f_{\mathrm{o}},
$$

where $k$ is the number of taxi drivers' successfully taking passengers in the urban area per hour. Finally, the decisionmaking model for taxi drivers is derived by comparing the value of the income from waiting in the airport parking lot and returning to the city directly.

When $R_{\text {wait }}>R_{\text {go }}$, the taxi driver should choose to wait in the parking lot.

When $R_{\text {wait }}<R_{\text {go }}$, the taxi driver should choose to return to the city to pick up passengers directly.

When $R_{\text {wait }}=R_{\text {go }}$, the taxi driver should choose to wait in the parking lot or return to the city to pick up passengers directly.

2.3. Quantitative Analysis. It is now assumed that the number of passengers waiting in the parking lot is 50, the number of taxis is 20 , and the airport correlation coefficients $a_{0}=1, n_{0}=0.5, n_{1}=n_{2}=0.25, \phi=60$. The passenger carrying distance in the district is 12 kilometres, and the passenger carrying distance in the urban area is 4 kilometres. The data are related to taxi fare $k=2, F=9, f_{\mathrm{o}}=0.6, f=2$, and $d=2$. Then, a scenario analysis can be performed and give a driver's decision in the current situation.

Based on known conditions, passengers' waiting times are

$$
\begin{aligned}
t_{C} & =(n-1) t_{0}+t_{1}=(50-1) \times 30+50 \times 60 \\
& =4470 \mathrm{~s}=1.242 \mathrm{~h} .
\end{aligned}
$$

The driver's waiting time is

$t_{D}=\left(\frac{\left(N_{C}\right)^{(1 / 2)-n_{1}}\left(N_{D}\right)^{(1 / 2)-n_{2}}}{a_{0}(\phi)^{n_{0}} \cdot\left(t_{C}\right)^{n_{1}}}\right)^{1 / n_{2}}=\left(\frac{50^{0.25} \times 20^{0.25}}{60^{0.5} \times 1.242^{0.25}}\right)^{4}=0.224 h$.

The driver's waiting profit is

$$
\begin{aligned}
R_{\text {wait }} & =\left(D_{D}-d\right) \cdot f+F-D_{D} \cdot f_{o}-E \cdot t_{D}, \\
R_{\text {wait }} & =(12-2) \times 2+9-12 \times 0.6-15 \times 0.224 \\
& =18.44 \text { yuan. }
\end{aligned}
$$
is

The driver's profit from returning to urban area directly

$$
\begin{aligned}
R_{\text {go }} & =k\left(\left(d_{D}-d\right) \cdot f+F-d_{D} \cdot f_{\mathrm{o}}\right)-D_{D} \cdot f_{\mathrm{o}}, \\
R_{\mathrm{go}} & =2 \times((4-2) \times 2+9-4 \times 0.6)-12 \times 0.6 \\
& =14 \text { yuan }<18.44 \text { yuan. }
\end{aligned}
$$

Therefore, under the current circumstances, the driver should choose to wait in the parking lot at the airport.

\section{Results and Discussion}

3.1. Applying the Decision-Making Model for Taxi Drivers to Practical Condition. The relevant data of taxis in Chengdu on a certain day have been collected. By combining the model established to simulate the condition, the rationality of the model and its dependence on relevant factors are analyzed by combining the BP neural network. 
TABle 1: Explanation for notations.

\begin{tabular}{|c|c|}
\hline Notation & Definition \\
\hline$x_{i}$ & Factor of number of passengers in the parking lot \\
\hline$t_{C}$ & Passenger's waiting time \\
\hline$t_{D}$ & Driver's waiting time in the parking lot \\
\hline$t_{0}$ & $\begin{array}{c}\text { Difference between the time taking the last taxi to pick up a passenger and the time taking the next taxi to pick up a passenger in } \\
\text { the parking lot }\end{array}$ \\
\hline$t_{1}$ & Boarding time of passengers \\
\hline$n$ & Number of passengers who are waiting for taxis \\
\hline$n_{1}$ & Airport position coefficient 1 \\
\hline$n_{2}$ & Airport position coefficient 2 \\
\hline K & Waiting time coefficient \\
\hline$A$ & Airport size eigenvalue \\
\hline$N_{C}$ & Number of passengers in the parking lot at some point \\
\hline$N_{D}$ & Number of taxis in the parking lot at some point \\
\hline$a_{0}$ & Airport position coefficient 3 \\
\hline$\phi$ & Airport terminal size coefficient \\
\hline$n_{0}$ & Airport position coefficient 4 \\
\hline$C_{\text {wait }}$ & Driver's waiting cost \\
\hline E & Expected revenue per hour while the driver waits \\
\hline$R_{\text {wait }}$ & Driver's waiting revenue in the parking lot \\
\hline$D_{D}$ & Distance a driver picking up passengers from airport to city \\
\hline$d$ & Mileage of taxi starting price \\
\hline$f$ & The fare per kilometre beyond the starting mileage \\
\hline$F$ & Taxi starting price \\
\hline$f_{o}$ & Fuel cost per kilometre of taxi \\
\hline$R_{\mathrm{go}}$ & Revenue for drivers returning directly to the city to pick up passengers \\
\hline$d_{D}^{80}$ & Distance of picking up passengers in the city \\
\hline$k$ & Successful times of taxi drivers in picking up passengers per hour in the city \\
\hline$R_{D}$ & Priority of a taxi \\
\hline$t_{1}^{i}$ & Passenger boarding time in line $i$ \\
\hline$t_{D}^{1, j}$ & Waiting time of the $j$ th taxi in line $i$ at some point \\
\hline$p_{i}$ & Priority of the first taxi in line $i$ \\
\hline$\widehat{g}_{l}$ & Probability of choosing the first taxi in line $i$ \\
\hline$g_{i}$ & Relative weight for line $i$ \\
\hline$r_{s}$ & Standardized relative weights for nonempty line $i$ \\
\hline
\end{tabular}

By querying relevant information, we get the information shown in Table 2.

By looking up the relevant data of the Chengdu Shuangliu Airport, this paper uses the BP neural network algorithm, as shown in Figures 2-4, to construct a correlation model of the number of flights, the passenger flow number, the number of passengers in the parking lot, and the number of taxis in the parking lot for one day:

$$
\mathrm{Y}_{\text {predict }}=\operatorname{sim}\left(\text { network } 1, \mathrm{x}_{\text {predict }}\right) \text {. }
$$

According to this relationship model, a specific set of time points is selected, and the corresponding number of passengers and the number of taxis in the parking lot have been outputted, and further data analysis is performed on the model to verify the rationality of the model and find the dependence of related factors.

3.2. Sensitive Analysis of First Stage. By selecting the time point set, the number of passengers and taxis in the parking lot of the Chengdu Shuangliu Airport has been obtained in this paper: 18,$4 ; 41,13 ; 41,33 ; 57,27 ; 57,37 ; 57,47 ; 83,34$; 83,$44 ; 95,42$. According to the decision-making model for taxi drivers established above and calculated through Matlab, the corresponding passenger waiting time value, taxi driver waiting time value, profit of taxi drivers' waiting in the parking lot and directly returning to the urban area can be derived, as shown in Table 3:

According to the heat map of Baidu map and the crowd distribution map, the possible destinations for taxi drivers from the airport are selected, and the probability of going to the destination is simulated by the heat map [26], as shown in Figure 5.

From this, the normal distribution relationship between probability of the passengers going to the destination and the distance from airport to the city (or from one place to the destination in the city have been obtained. The average carrying distance from the airport to the urban area is 11.54 and the standard deviation is 2.27 and the average distance within the city is 4 and the standard deviation is 1.1 , as shown in Figure 6.

The rationality and correlation of the practical data acquired from the Shuangliu Airport can be analyzed by the established decision-making model for taxi drivers:

(1) By comparing the value of passenger waiting time, it can be found that the passengers' waiting time 
TABLE 2: Coefficient value of the decision-making model for taxi drivers.

\begin{tabular}{|c|c|c|}
\hline Variable definition & Value & Unit \\
\hline Terminal area at Chengdu Shuangliu International Airport & 50 & $\begin{array}{l}\text { Million square } \\
\text { meter }\end{array}$ \\
\hline Average queue time for taxi drivers in the parking lot & 2 & Hour \\
\hline Waiting time for passengers in line & 20 & Minute \\
\hline Fuel cost of taxi & $6.67[24]$ & Yuan/liter \\
\hline Boarding time for passengers & 60 & Second \\
\hline Fuel consumption of taxi & 0.1 & Liter/kilometre \\
\hline Airport position coefficient 1 & 0.25 & Dmnl \\
\hline Airport position coefficient 2 & 0.25 & Dmnl \\
\hline Airport position coefficient 3 & 1 & Dmnl \\
\hline Airport position coefficient 4 & 0.5 & Dmnl \\
\hline Mileage of taxi starting price & $2[25]$ & Kilometre \\
\hline Taxi starting price & $9[22]$ & Yuan \\
\hline Fuel cost per kilometre of taxi & 0.667 & Yuan \\
\hline Successful times of taxi drivers in picking up passengers per hour in the city & 2 & Times \\
\hline Expected revenue per hour while the driver waits & 10 & Yuan \\
\hline $\begin{array}{l}\text { Difference between the time taking the last taxi to pick up a passenger and the time taking the next taxi to } \\
\text { pick up a passenger in the parking lot }\end{array}$ & 30 & Second \\
\hline
\end{tabular}

$$
\begin{aligned}
Y_{\text {predict }}= & \operatorname{sim}\left(\text { network1, } x_{\text {predict }}\right) \\
& \text { Hidden layer }
\end{aligned}
$$

(H)

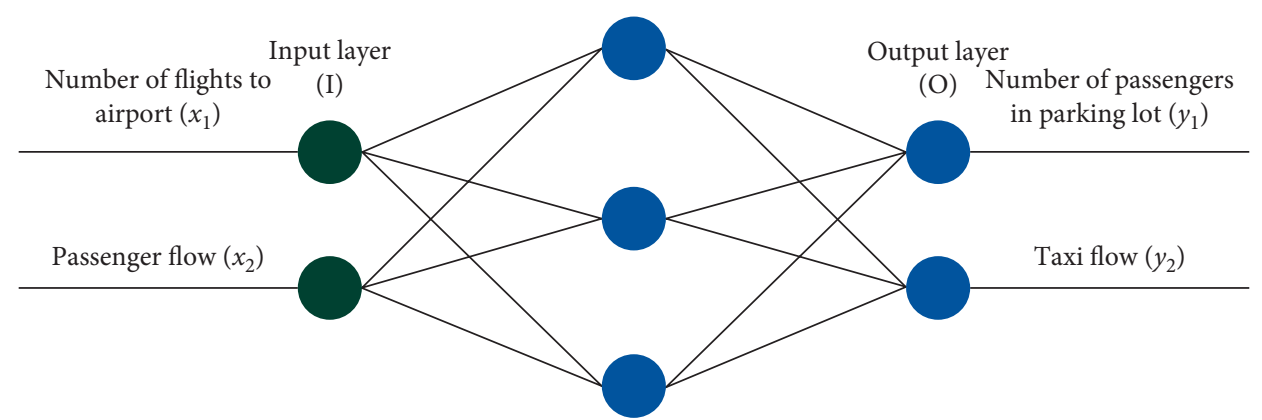

Figure 2: BP network flow diagram.

increases with the growing number of passengers in the parking lot and does not change with the increasing number of taxis in the parking lot. This result is reasonable, because the number of taxis in the parking lot has always been sufficient, so there will not be a shortage of taxis, which will not affect the waiting time of passengers. Meanwhile, the queuing and waiting mechanism makes it reasonable for the waiting time of passengers to rise as the number of passengers in the parking lot increases.

(2) By comparing the value of taxi driver waiting time, the waiting time of taxi drivers grows with the increasing number of passengers in the parking lot and also increases with the number of taxis in the parking lot. And the impact of the number of taxis in the parking lot on the taxi driver's waiting time is greater than the impact of the number of passengers. Such result is reasonable because the increase in the number of passengers in the parking lot and the increase in the number of taxis will increase the load in the airport and raise the waiting time for taxi drivers. At the same time, the number of taxis has a greater impact on the driver's waiting time, because the taxi drivers also need to wait in line for a pickup. Therefore, the number of taxis will directly affect the waiting time for taxi drivers in the parking lot. Relatively speaking, the impact of the number of passengers on the waiting time for taxi drivers is small.

(3) By comparing the waiting income of taxi drivers with the choice of returning to urban area, it can be revealed that when the carrying distance is chosen as the maximum probability is reached $\left(D_{D}=11.54\right.$, $\left.d_{D}=4\right)$, the taxi drivers' waiting income will change with the changes in the number of passengers and taxis in the parking lot, and the income of taxi drivers returning directly to the city will not change. This is because the driver's waiting income is closely related to the waiting time of the driver, and the waiting time is affected by the number of passengers and the 


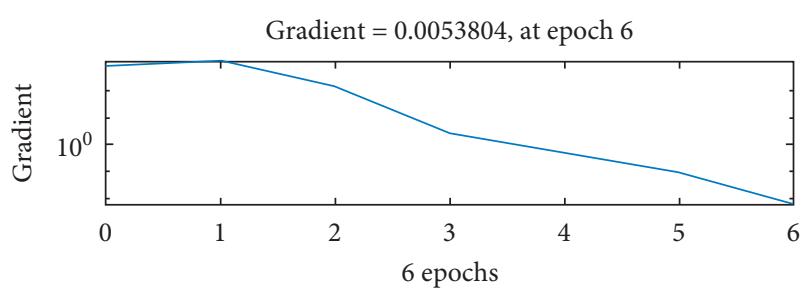

$\mathrm{Mu}=0.001$, at epoch 6

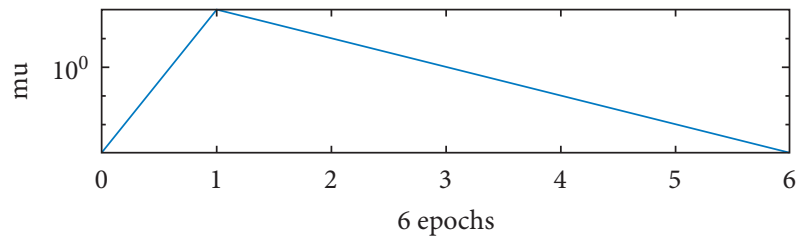

Validation checks $=6$, at epoch 6

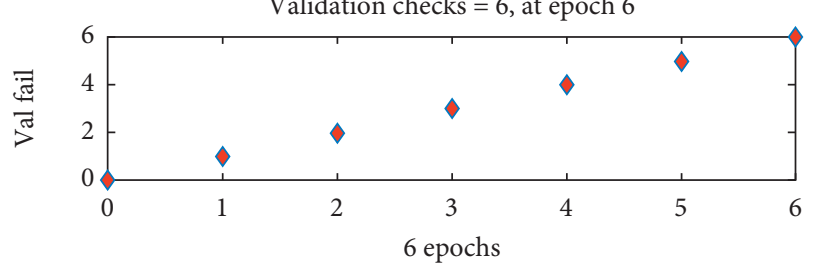

FIGURE 3: BP network result diagrams.

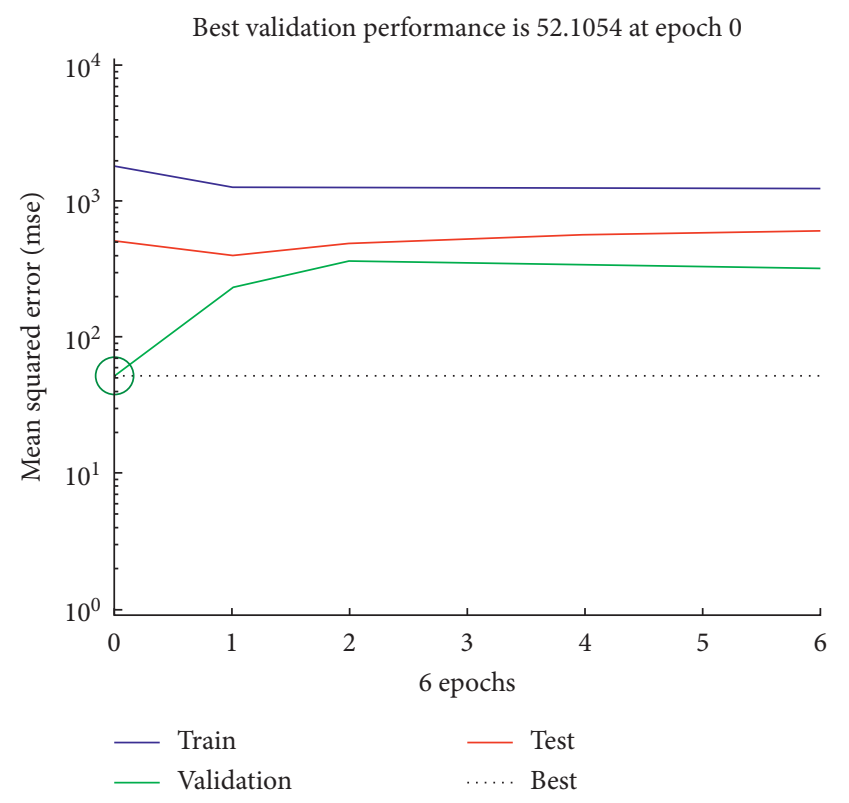

Figure 4: BP network model diagram.

number of taxis. The income of drivers who drive directly to the urban area is only affected by the carrying distance from the airport to the urban area and within the urban area. When the values of $D_{D}$ and $d_{D}$ that affect the passenger distance remained the same, drivers' earnings will not be affected.

(4) At the same time, for the taxi driver's waiting income, compare the number of passengers with the number of taxis data set $(41,13 ; 41,33$ or 57,$27 ; 57$, $37 ; 57,47)$. When the number of passengers in the parking lot remains unchanged, the driver's waiting income decreases as the number of taxis in the parking lot increases. Considering that the larger the number of taxi drivers in the parking lot, the greater the waiting cost of taxi drivers, therefore the rationality of this result can be verified by reducing the waiting income of drivers. When the number of passengers and taxis is $(57,47)$, it can be found that the driver's waiting income at this time is 12.6287 yuan, which is very close to the average income of the driver who directly goes to the city to pick passengers. Based on the mathematical relationship of the BP neural network established in Matlab, the number of passengers and taxis is $(57,49)$, and the driver's waiting income at this time is 11.87 yuan, which is slightly larger than the average income of the drivers going to the city, which means that when the number of passengers is stable at 57 and the number of taxis in the parking lot is greater than 49 , the drivers should choose to return to the city to pick up passengers directly.

(5) Furthermore, comparing the number of passengers and the number of taxis data set $(41,33 ; 57,37 ; 83$, 34 ), it can be revealed that when the number of taxis stabilizes, the driver's waiting income increases with the declining number of passengers. Considering that when the number of passengers increases, the waiting cost of the driver increases, therefore the validity of this result can be verified by reducing the waiting income of the driver. When the number of passengers and taxis is $(83,34)$, it can be found that the driver's income at this time is 11.3141 yuan, which is approximately equal to the average income of the driver who directly goes to the city. It indicates that when the number of taxis is stable at around 34 and the number of passengers is greater than 83 , the drivers should choose to return directly to the city to pick up passengers. According to the calculation of Matlab, the relationship between the product of the number of passengers and the traffic volume and the drivers' profit can be derived from Table 4 .

(6) Consider the above two situations comprehensively, we can calculate the product of the number of passengers and the number of taxis to make a judgment on the choice of the drivers. By comparing the product of the number of passengers and the number of taxis and the driver's waiting income at the airport, it can be found that the driver's waiting income decreases as the product of the number of passengers and taxi increases. Comparing the passenger number and taxi number data sets of $(83,34$; $83,44)$, it can be found that when the product of passenger number and taxi number is 2822 , the driver's waiting income is 13.61 yuan, which is greater than the average income of returning to the urban area, which is 11.83 yuan. When the product of the number of passengers and the number of taxis is 3652 , the waiting income of the driver is 9.32 yuan, which is less than the average income of the driver 
TABLE 3: The relationship between waiting time and diver's revenue.

\begin{tabular}{lccccc}
\hline $\begin{array}{l}\text { Number of passengers } \\
\text { in the parking lot } \\
\text { (person) }\end{array}$ & $\begin{array}{c}\text { Taxi } \\
\text { flow } \\
\text { (car) }\end{array}$ & $\begin{array}{c}\text { Passenger's } \\
\text { waiting time } \\
\text { (hour) }\end{array}$ & $\begin{array}{c}\text { Driver's waiting time } \\
\text { in the parking lot } \\
\text { (hour) }\end{array}$ & $\begin{array}{c}\text { Driver's waiting } \\
\text { revenue in the } \\
\text { parking lot (yuan) }\end{array}$ & $\begin{array}{c}\text { Average revenue for drivers } \\
\text { returning directly to the city to pick } \\
\text { up passengers (yuan) }\end{array}$ \\
\hline 18 & 4 & 0.158 & 0.020 & 19.27 & 11.83 \\
41 & 13 & 0.350 & 0.046 & 17.99 & 11.83 \\
41 & 33 & 0.350 & 0.428 & 15.19 & 11.83 \\
57 & 27 & 0.483 & 0.784 & 11.63 & 11.83 \\
57 & 37 & 0.483 & 1.108 & 8.39 & 11.83 \\
57 & 47 & 0.483 & 0.376 & 15.71 & 11.83 \\
83 & 34 & 0.700 & 0.586 & 13.61 & 11.83 \\
83 & 44 & 0.700 & 1.014 & 9.32 & 11.83 \\
95 & 42 & 0.800 & 0.744 & 12.03 & \\
\hline
\end{tabular}
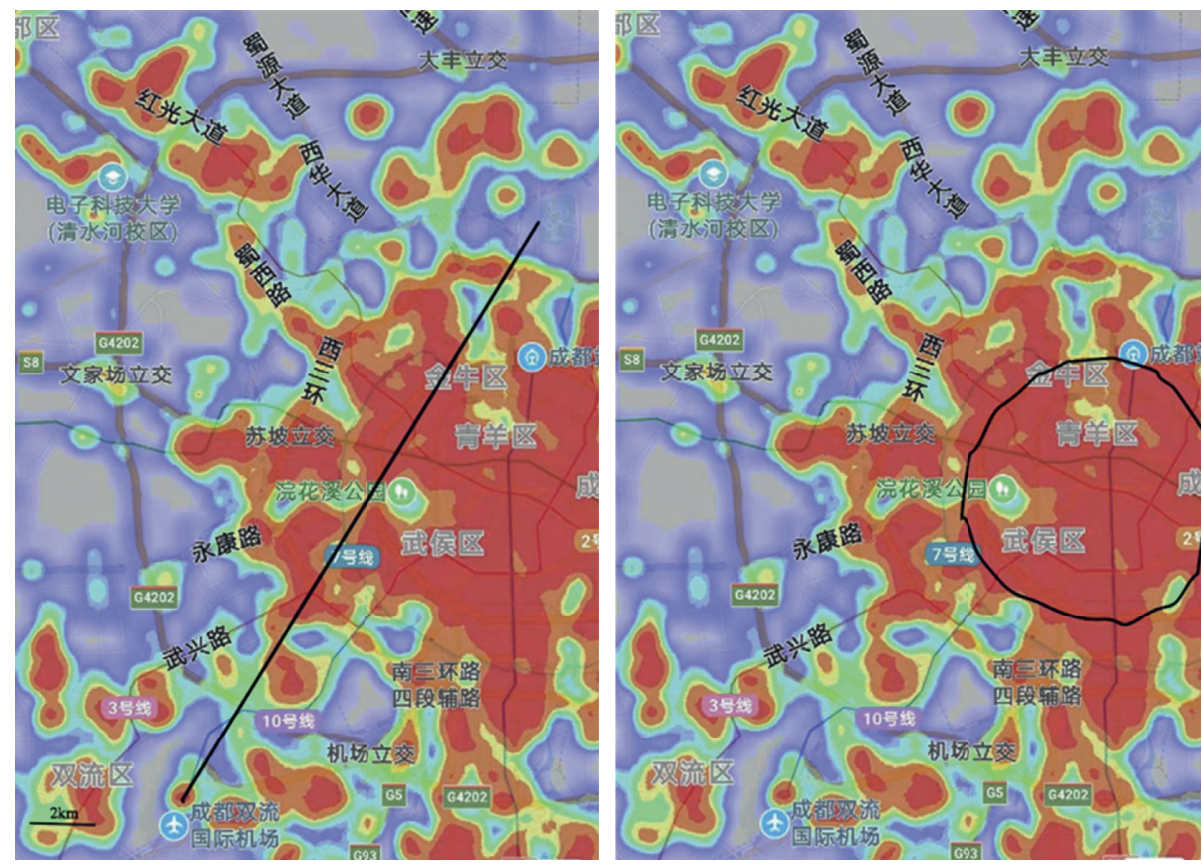

FIGURE 5: Heat map of population distribution in Chengdu.
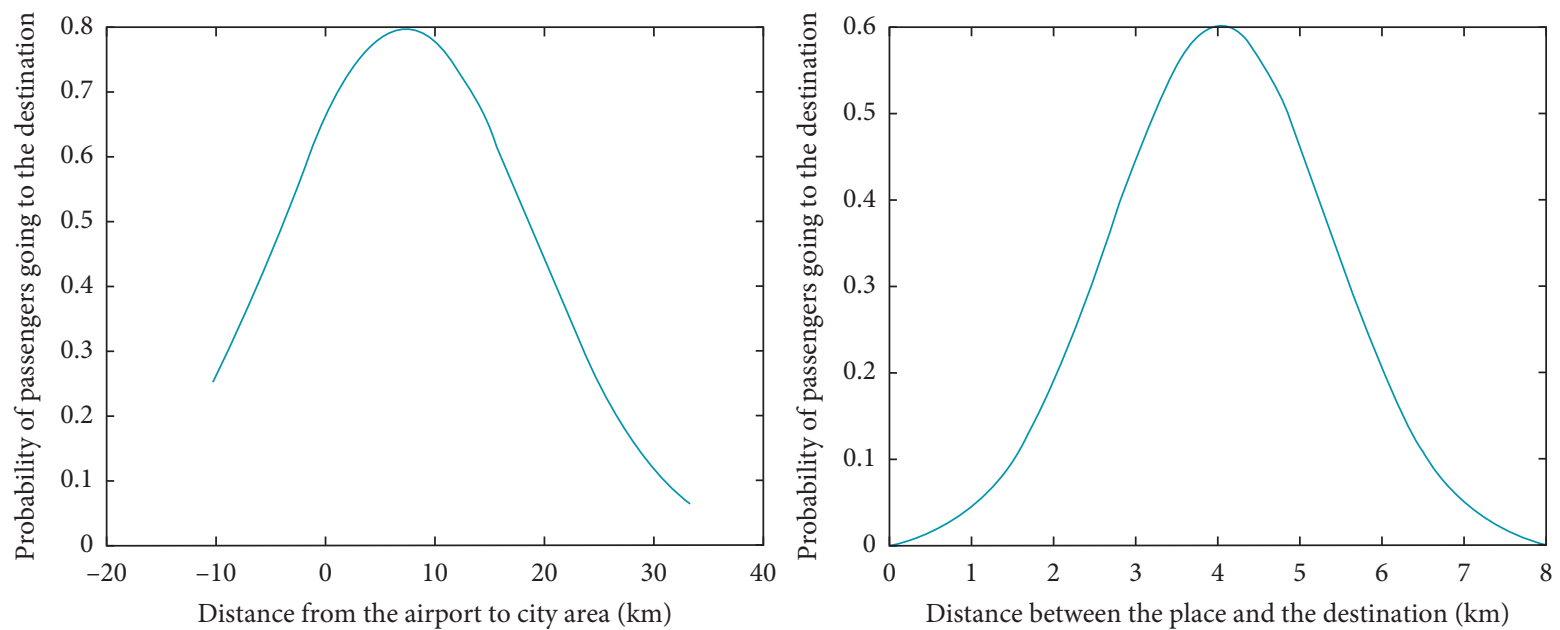

Figure 6: Normal distribution of the distance. 
who returns directly to the urban area of 11.83 yuan. Therefore, it can be concluded that there is a mathematical relationship between the driver's waiting income and the product of the number of passengers and the number of taxis. By looking for the product of the number of passengers and taxis corresponding to the driver's waiting income of approximately 11.83 yuan, the driver's choice can be judged.

(7) Further comparing the product data set of the above two cases $(57,49 ; 83,34)$, it can be found that $57 \times 49=2793$ and $83 \times 34=2822$. So, when the product of the number of passengers and the number of taxis belongs to the range of $[2793,2822]$, while the driver's waiting income is within the range of [11.61, 11.87]. When the product value is equal to 2793 , the driver's waiting income is 11.87 yuan, which is closer to the average income of the drivers returning to the urban area, which is 11.83 yuan. So, the target product value is greater than 2793 and close to 2793. Based on this conclusion, the product value is determined to be 2800 .

Therefore, after the first-stage sensitive analysis, the taxi driver's decision is as follows.

When the product of the number of passengers and the number of taxis $N_{C} \cdot N_{D}$ is greater than 2800 , the taxi driver should choose to return to the city to pick passengers;

When the product of the number of passengers and the number of taxis $N_{C} \cdot N_{D}$ is less than 2800 , the taxi driver should choose to wait in the parking lot of the airport.

When the product of the number of passengers and the number of taxis $N_{C} \cdot N_{D}$ is equal to 2800 , the taxi driver should choose to return directly to the city to pick up passengers or wait in the parking lot at the airport. And the current decision-making model for taxi drivers for taxi drivers can be written as

$$
D=f_{1}\left(N_{C}, N_{D}\right),
$$

where $N_{C}$ is the number of passengers and $N_{D}$ is the number of drivers.

\subsection{Establishment of Optimization Model of Dispatching} Efficiency. In order to obtain an ideal optimization model of dispatching efficiency, this paper introduces the highest response ratio next (HRRN) scheduling strategy in processor scheduling. Based on this algorithm, the dynamic priority calculation formula is

$$
\text { priority }=\frac{\text { wait time }+ \text { service time }}{\text { service time }} \text {. }
$$

In this question, the waiting time may correspond to the time that the taxi driver waits for passengers in the parking lot, and the service time may correspond to the passenger boarding time:

$$
\text { priority }=\frac{\text { wait time of drivers }+ \text { pick }- \text { up time of passengers }}{\text { pick }- \text { up time of passengers }} .
$$

Because the passenger boarding time is used as the denominator, passengers with faster boarding time will be given the priority, and because the driver's waiting time in the parking lot appears in the numerator, the driver with a longer waiting time will also be more preferable, so as to prevent the condition that one driver remains waiting.

In the parking lot of the airport, who can pick passengers first depends on the line in which the car is located (the boarding time in different lines are different) and the waiting time of the taxis. At the same time, in most cases, the longer time a taxi driver waits in the lines, the closer the taxi should be to the passenger pickup point. And the final priority calculation formula can be expressed as [14]

$$
P_{D}=1+\frac{t_{D}^{i, j}}{t_{1}^{i}}
$$

where $P_{D}$ is the priority of a taxi, $t_{1}^{i}$ is the boarding time of the passenger corresponding to line $i$, and $t_{D}^{i, j}$ is the waiting time of the $j$ th car in line $i$ at a certain moment.

In order to further optimize the ride rationality of the entire parallel line, this paper optimizes the entire scheduling algorithm based on the original HRRN scheduling theory and turns it into a probability-based dynamic priority scheduling algorithm. In this algorithm, the priority of each process depends on the service time and the time waiting for service. The specific optimization method is as follows:

Assume that the priority of the first taxi in the $i$ th line is $p_{i}$, when a taxi in the $i$ th line successfully drives away, the system will randomly select one from the first taxi in the two lines to serve as the next taxi for the passengers. The probability that the first car in the $i$ th line is selected is $\widehat{g}_{i}$. Before selecting, we need to sort the size of $p_{i}$ and record this order as

$$
P=\left[p_{l 1}, p_{l 2}\right],
$$

where the subscript is $l_{i}$, which is the relative weight of the $i$ th line.

The calculation method of $\widehat{g}_{i}$ is as follows:

First consider the relative weight of the $i$ th line, denoted as $g_{i}$. According to the different lines, the definition is as follows [15]:

$$
\begin{aligned}
& g_{i}=p_{l_{i}}, \quad i=1, \\
& g_{i}=p_{l_{i}} \prod_{j=1}^{i-1}\left(1-p_{l_{j}}\right), \quad i>1 .
\end{aligned}
$$

For nonvoid $i$ th line, its standardized relative weight is defined as follows:

$$
\widehat{g}_{i}=\frac{r_{i}}{\sum_{j_{\text {non-void }}} r_{j}} .
$$

Therefore, in order to optimize the efficiency of airport rides, from the perspective of taxi drivers, the management system should prefer to choose taxis with longer waiting times and higher priority taxis to carry passengers; from the perspective of passengers, the management department should choose passengers with shorter boarding times.

3.4. Quantitative Analysis. Now, suppose there are 20 taxis and 50 passengers waiting in the parking lot and use this model to simulate the scene, as shown in Figure 7: 
TABLE 4: The relationship between passenger flow and the driver's revenue [27].

\begin{tabular}{lcccc}
\hline $\begin{array}{l}\text { Number of passengers in } \\
\text { the parking lot (person) }\end{array}$ & $\begin{array}{c}\text { Taxi } \\
\text { flow } \\
\text { (car) }\end{array}$ & $\begin{array}{c}\text { Product between number of } \\
\text { passengers and taxi flow } \\
\text { (Person*Car) }\end{array}$ & $\begin{array}{c}\text { Driver's waiting } \\
\text { revenue in the parking } \\
\text { lot (yuan) }\end{array}$ & $\begin{array}{c}\text { Average revenue for drivers returning } \\
\text { directly to the city to pick up } \\
\text { passengers (yuan) }\end{array}$ \\
\hline 18 & 4 & 72 & 19.27 & 11.83 \\
41 & 13 & 533 & 17.99 & 11.83 \\
41 & 33 & 1353 & 15.19 & 11.83 \\
57 & 27 & 1539 & 11.63 & 11.83 \\
57 & 37 & 2109 & 8.39 & 11.83 \\
57 & 47 & 2679 & 15.71 & 11.83 \\
83 & 34 & 2822 & 13.61 & 11.83 \\
83 & 44 & 3652 & 9.32 & 11.83 \\
95 & 42 & 3990 & 12.03 & 11.83 \\
\hline
\end{tabular}

$$
\begin{aligned}
t_{c}^{1} & =(50-1) \times 30+60=1530 s=0.425 h \\
t_{D}^{1, j} & =\left(\frac{(50)^{0.25} \times(20)^{0.25}}{(50)^{0.5} \times(0.425)^{0.25}}\right)^{4}=0.941 h, \\
t_{c}^{2} & =(50-1) \times 30+90=1560 s=0.433 h, \\
t_{D}^{1, j} & =\left(\frac{(50)^{0.25} \times(20)^{0.25}}{(50)^{0.5} \times(0.433)^{0.25}}\right)^{4}=0.924 h, \\
p_{1} & =1+\frac{t_{D}^{1, j}}{t_{1}^{1}}=2.21, \\
p_{2} & =1+\frac{t_{D}^{2, j}}{t_{1}^{2}}=2.13 .
\end{aligned}
$$

Suppose $p_{l_{1}}=0.8, p_{l_{2}}=0.8, p_{l_{1}}=0.64$ :

$$
\begin{aligned}
& g_{1}=p_{l_{1}}=0.8, \\
& g_{2}=p_{l_{2}} \cdot\left(1-p_{l_{1}}\right)=0.64 \times 0.2=0.128, \\
& \widehat{g}_{1}=\frac{0.8 \times 2.21}{0.8 \times 2.21+0.128 \times 2.13}=86.6 \%, \\
& \widehat{g_{2}}=\frac{0.128 \times 2.13}{0.8 \times 2.21+0.128 \times 2.13}=13.4 \% .
\end{aligned}
$$

(2) improve the priority of taxis in line 2 so as to improve the use efficiency of line 2

With regard to granting "priority," the further suggestions can be as follows:

(1) Priority points can be added to allow returning taxis to preferentially enter these lines to take passengers so that these taxis can take a greater number of passengers per hour and increase their earnings

(2) The line can be divided into a long-distance line and a short-distance line, and the passenger entrance is separated. Passengers who need to take a long-distance ride line up at the long-distance passenger line, and passengers who need a short-distance ride queue in the short-distance passenger line. The management department can quickly divert taxis on different routes through these measures, which not only protects the revenue of taxis but also improves the passenger's riding efficiency.

Therefore, the current optimization model of dispatching efficiency can be drawn as

$$
P=f_{2}\left(t_{1}, t_{D}\right)
$$

where $P$ is the dispatching priority of a taxi, $t_{1}$ is the passenger's boarding time, and $t_{D}$ is the passenger's waiting time.

Since $t_{1}$ and $t_{D}$ are dependent on the passenger number $N_{C}$ and the taxi number $N_{D}$, the optimization model can be further written as

$$
P=f_{2}\left(N_{C}, N_{D}\right)
$$

the probability of the first car in the second line being selected is only $13.4 \%$. From such analysis, it can be concluded that the usage probability of the second line at a certain moment is much smaller than the usage probability of the first line. The reason is that passengers tend to choose the nearest line to get on the car to reduce the time required to get on the car.

Based on such conclusion, in order to maximize the overall riding efficiency, the management department should

(1) increase the relevant passages to reduce the time required for passengers to get online 2 and increase the use efficiency of line 2

3.5. Sensitive Analysis of Second Stage. Since the previous decision-making model for taxi drivers and optimization model of dispatching efficiency are based on one day in the Chengdu Shuangliu Airport, the models lack sensitiveness analysis on the different time in a year. Therefore, to make the further sensitive analysis, weather conditions and holiday will be taken into consideration.

By selecting the passenger number of the Labour Day (blue line) in the Chengdu Shuangliu Airport, the distribution of the passenger number is shown in Figure 8 in 


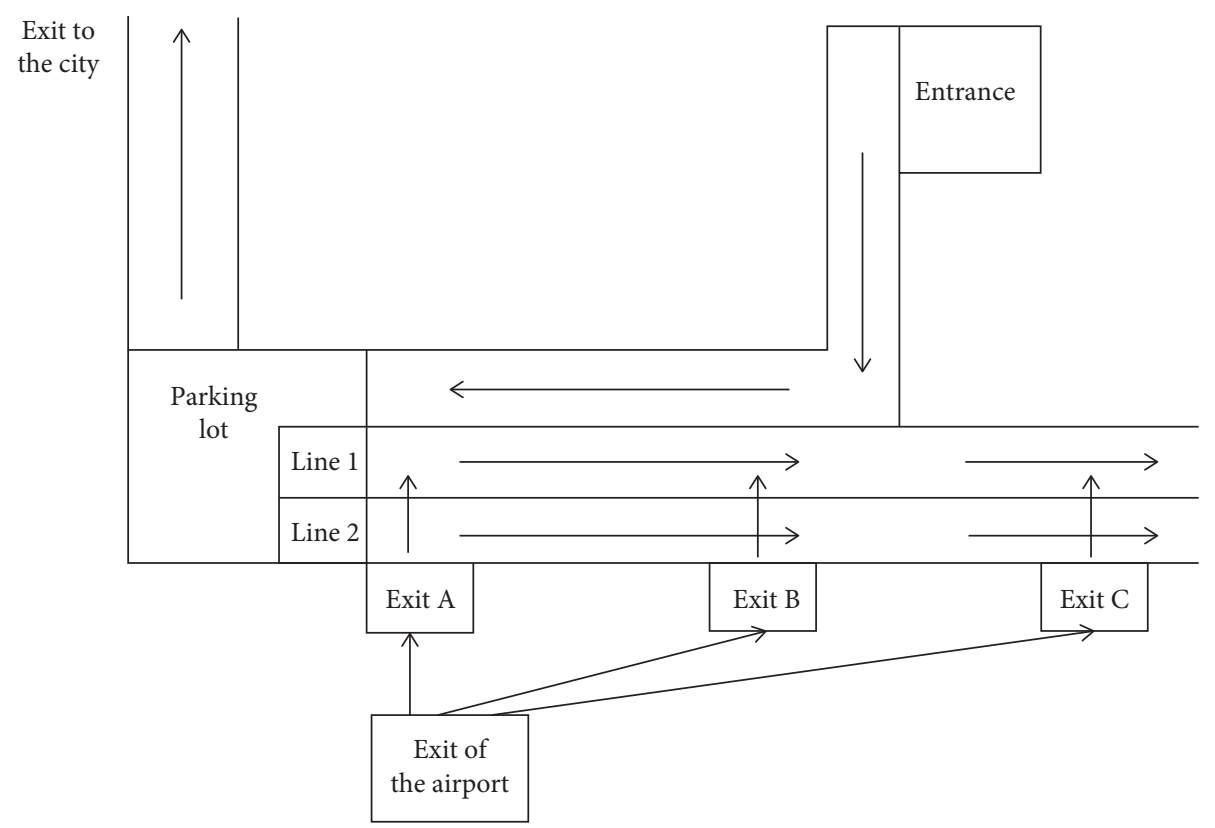

Figure 7: Simulation map of airport boarding area.

comparison with a normal workday (red line), where the workday is taken as the control day.

Compared with the passenger number on the control day, it can be found that the passenger number on holiday is visibly higher than one of normal days.

Similarly, as displayed in Figure 9, by selecting one rainy day (black line) in the Shuangliu Airport, the number of passengers is lower than the one on the day with sunny day (red line), where sunny day is determined to be the control weather condition.

Based on the abovementioned observations, conclusion can be drawn that the number of passengers is sensitive to holiday and weather condition.

Roh et al. adopted the regression model to simulate the impact of snow and temperature on the highway truck traffic [28] and acquired expected results. By gaining the experience from Roh's research, this paper will apply the regression model to further simulate the effect of weather condition and holiday on the number of passengers. To simulate the effect of weather condition and holiday, each factor will be divided into five levels including the control level.

3.5.1. Weather Condition. The weather condition will be divided into sunny day (control level), light rain (level 1), heavy rain (level 2), thundershower (level 3), and snowstorm (level 4). The number of passengers can be adjusted by multiplying one weather condition factor $k_{W}$, and the passenger number will be $N_{C} \cdot k_{W}$. By collecting typical data from the official website of the Chengdu Shuangliu Airport on the corresponding weather conditions, the comparison between the data and the prediction can be manifested from Figure 10.

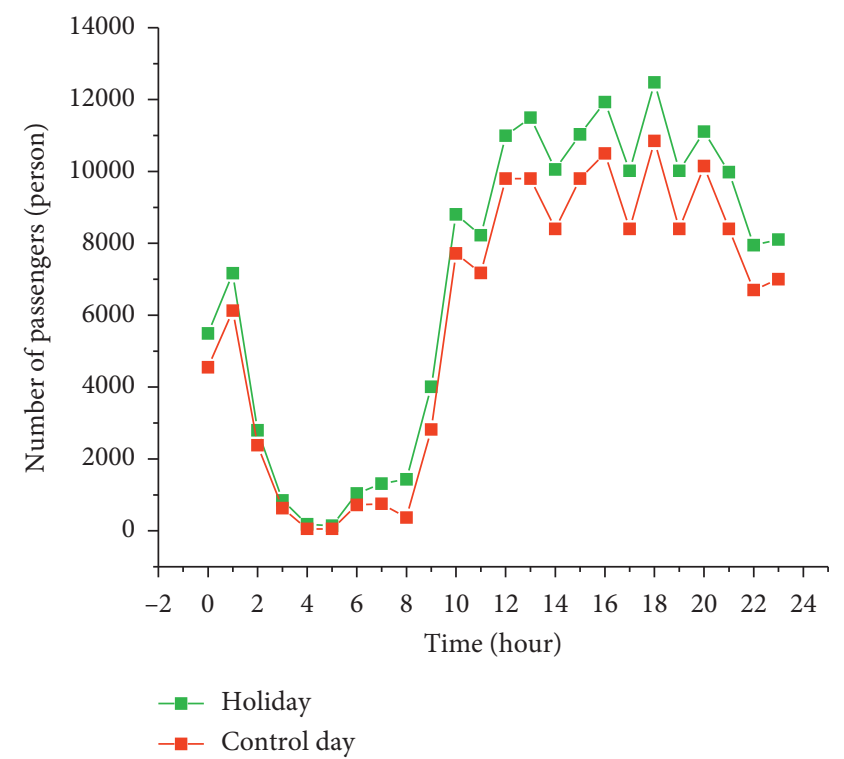

FIGURE 8: Comparison of the passenger number on control day and holiday.

In the graphs, the red lines are the control level and the blue lines and green lines are, respectively, for original data and for predictions. From the results, it can be seen that as the weather condition gets severer, the number of passengers drops, and the predictions fit the trend of the original data, where $k_{W}$ equals to $3,2.5,2$, and 1.5 , respectively, for weather condition level 1 , level 2 , level 3 , and level 4 .

3.5.2. Holiday Condition. The holiday condition will be divided into workday (control day), weekends (level 1), holiday with 3 days to 5 days (level 2), holiday with 7 days (level 3), and holiday with over 7 days (level 4). The number of passengers can be regulated by multiplying one holiday factor $k_{H}$, and the 


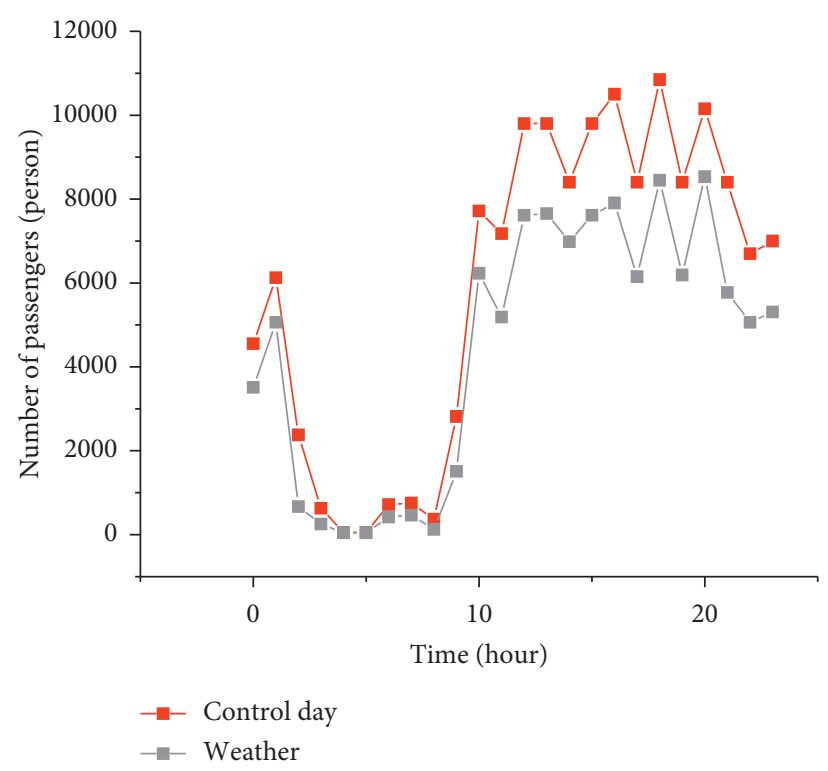

Figure 9: Comparison of the passenger number on control day and weather.
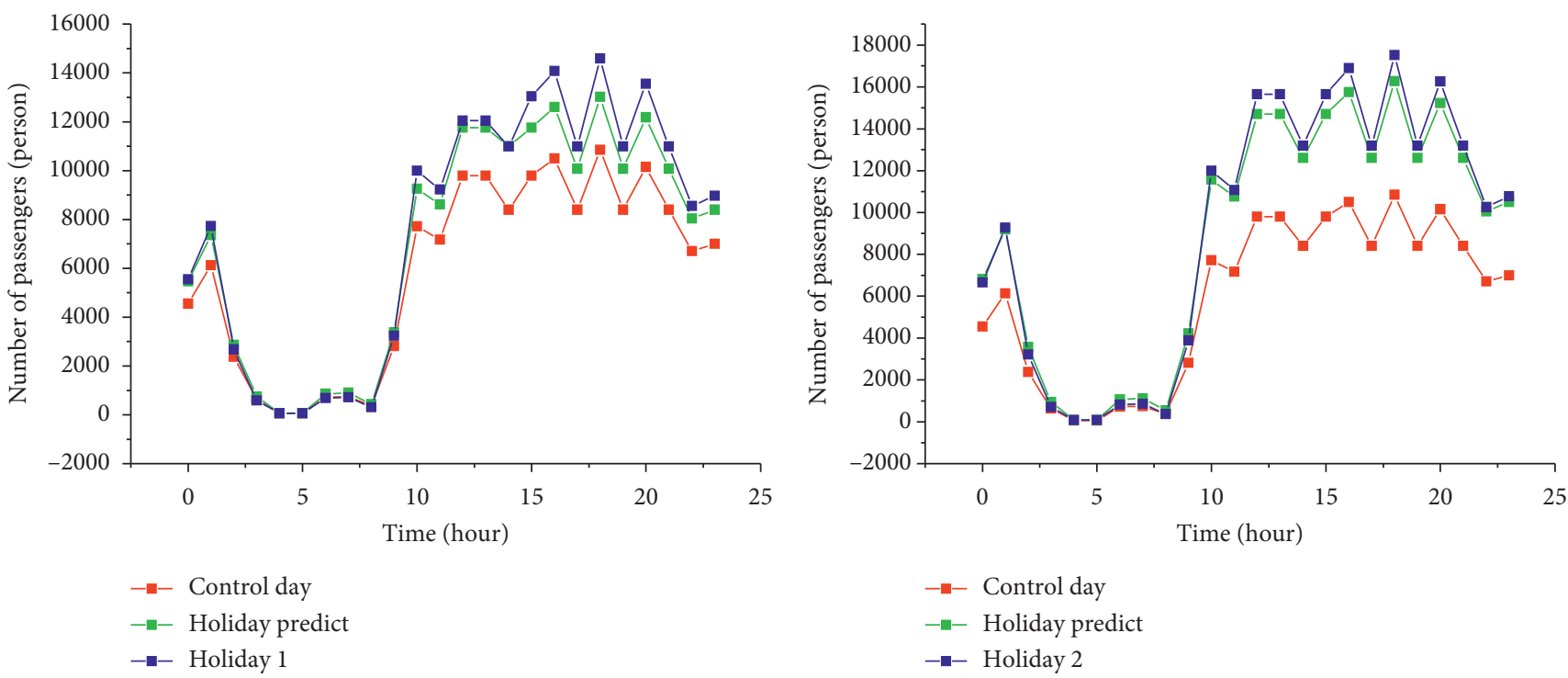

(a)

(b)

Figure 10: Continued. 


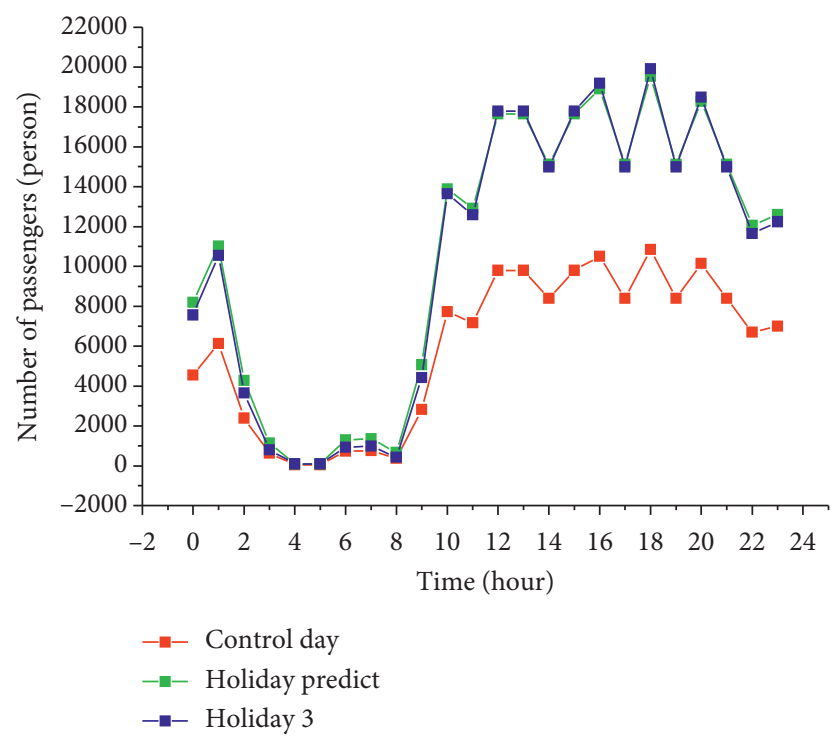

(c)

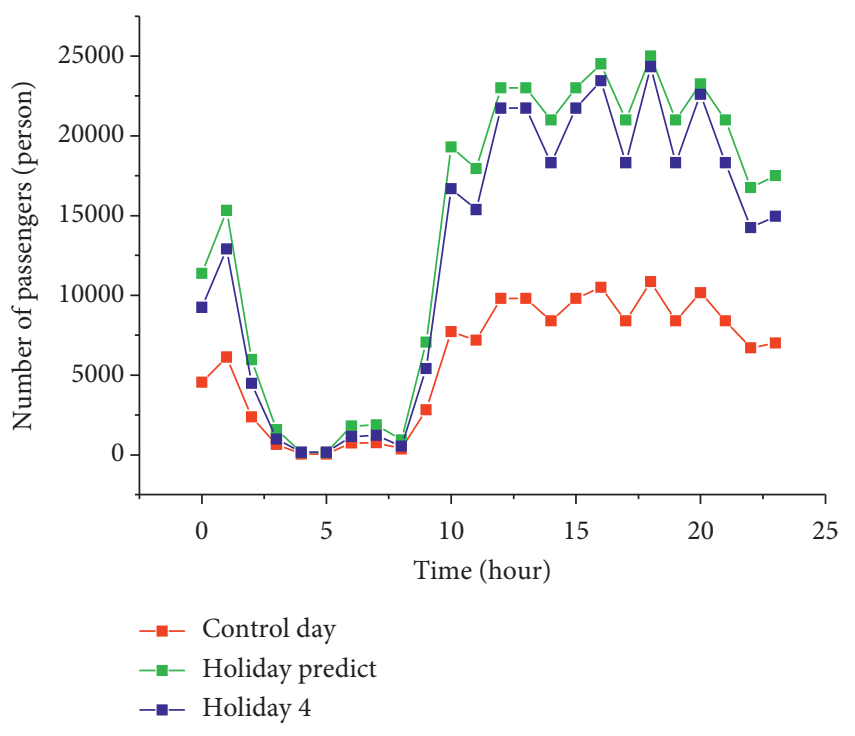

(d)

Figure 10: Comparison between data and prediction on weather condition from level 1 to level 4 .

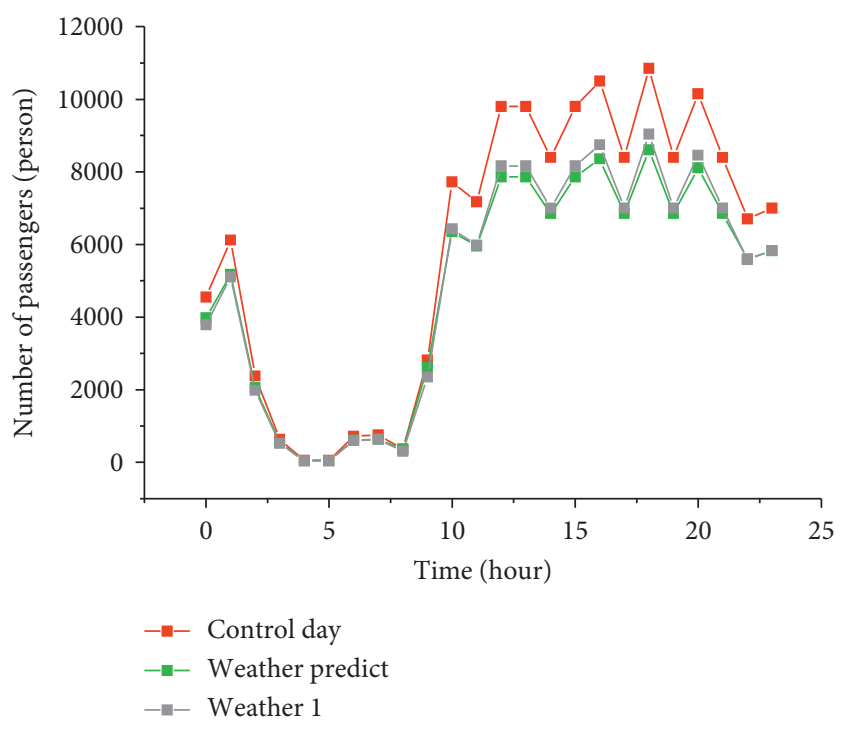

(a)

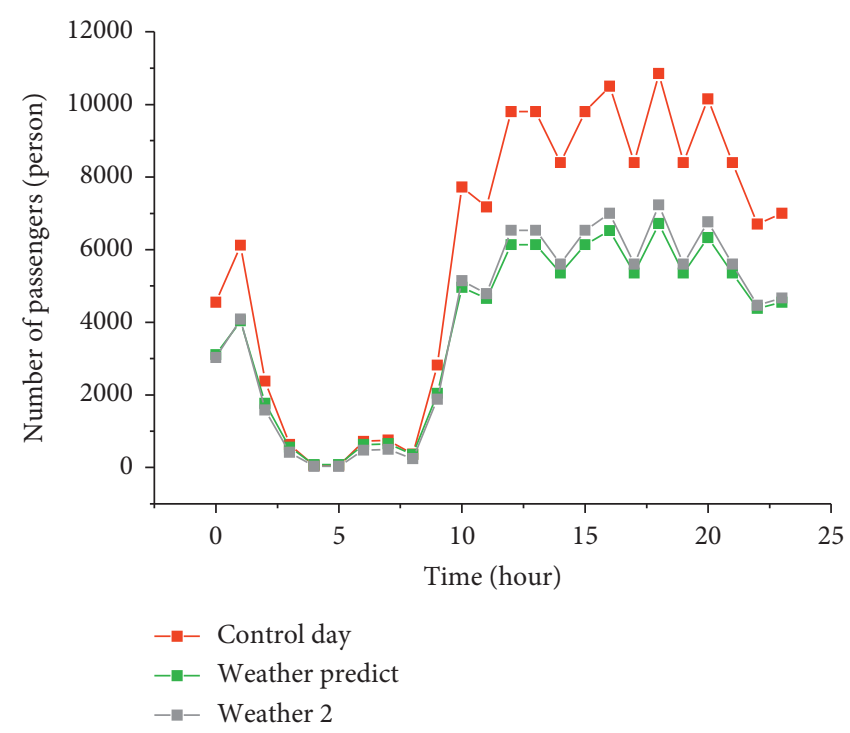

(b)

Figure 11: Continued. 


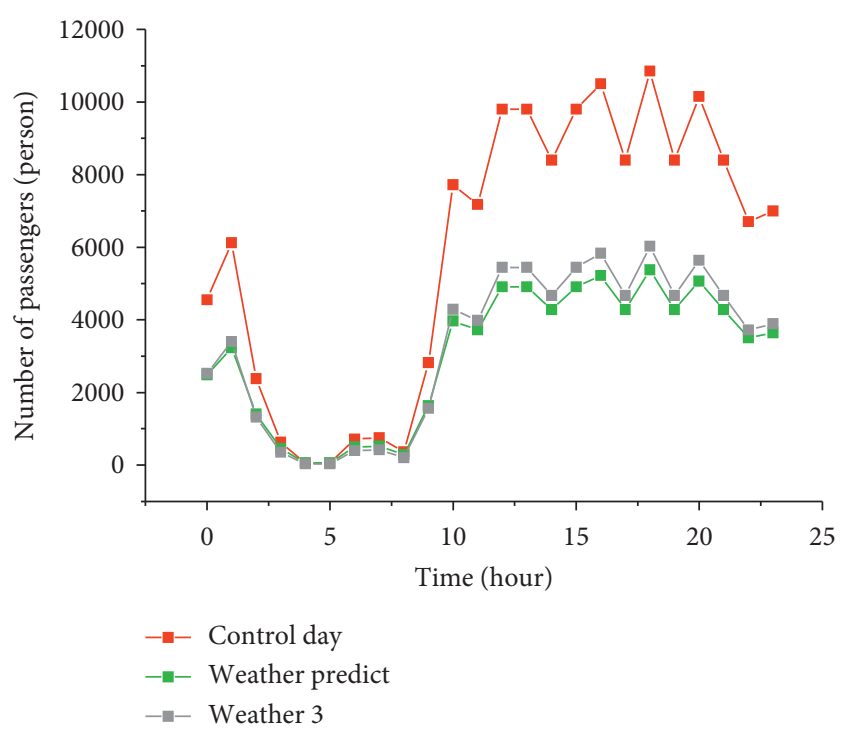

(c)

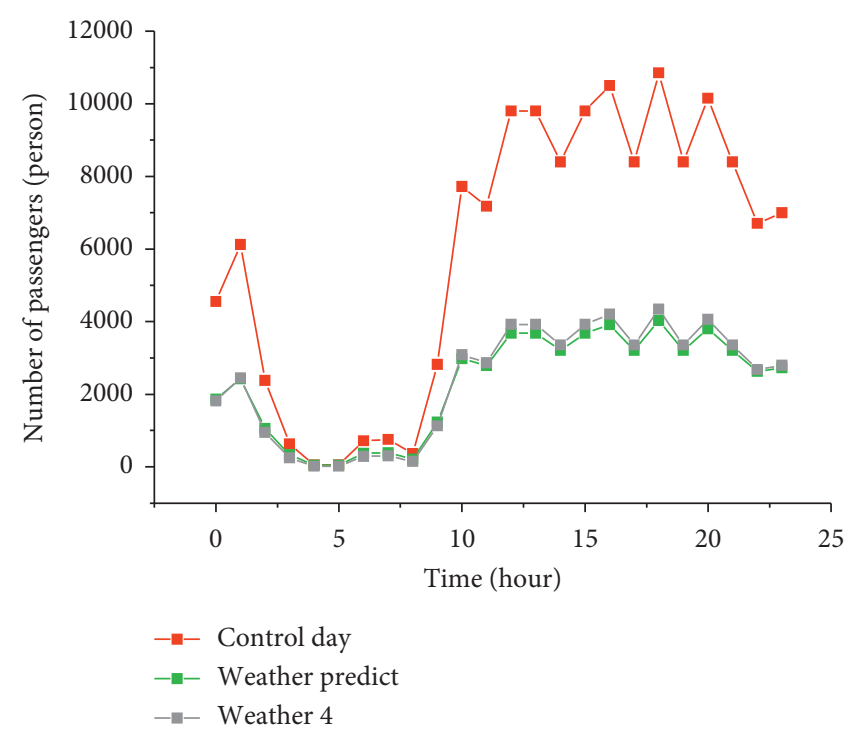

(d)

FIgURE 11: Comparison between data and prediction on holiday condition from level 1 to level 4 .

passenger number will be $N_{C} \cdot k_{H}$. By collecting typical data from the official website of the Chengdu Shuangliu Airport on the corresponding weather conditions, the comparison between the data and the prediction can be manifested from Figure 11.

In the graphs, the red lines are the control level and the blue lines and green lines are, respectively, for original data and for predictions. From the results, it can be seen that as the holiday period becomes longer, the number of passengers rises, and the predictions generally fit the original data, where $k_{H}$ equals to $5 / 6,2 / 3,5 / 9$, and $2 / 5$, respectively, for holiday condition level 1 , level 2, level 3, and level 4.

Therefore, from the discussed results, the number of passengers is sensitive to the weather condition and holiday period. Since the number of taxi drivers will be significantly influenced by the passenger number, the number of taxis will be sensitive to the weather condition and holiday period.

3.6. Final Model. Based on the previous discussions, the influence of weather condition can be deduced by a function $f_{W}(t)$, which depends on the time (date) $t$. And the impact of holiday period can be inferred by a function $f_{D}(t)$, which relies on time $t$ as well.

Then, the final taxi driver's decision model can be derived as

$$
\begin{aligned}
& D=f_{1}\left(N_{C}, N_{D}\right) \cdot f_{W}(t) \cdot f_{D}(t), \\
& D=f_{1}\left(N_{C} \cdot f_{W} \cdot f_{D}, N_{D} \cdot f_{W} \cdot f_{D}\right) .
\end{aligned}
$$

Since the number of taxis will be changed by the difference of the passenger number, the number of taxis will be a dynamic number:

$$
N_{D, i}=k(D) \cdot N_{D, i-1}
$$

where $k(D)$ is the influence factor caused by the change of passenger number.

And then, the final optimization model of dispatching efficiency can be obtained as

$$
\begin{aligned}
& P=f_{2}\left(t_{1, i}^{j}, t_{D, i}^{j}\right), \\
& P=k(D) \cdot f_{2}\left(N_{C}, N_{D}\right),
\end{aligned}
$$

where $P$ is the priority of a taxi at $j$ th line when the taxi number is $N_{D, i}$, and $t_{1, i}^{j}$ is the passengers' waiting time when the taxi number is $N_{D, i}$, and $t_{D, i}^{j}$ is the taxi driver's waiting time when the taxi number is $N_{D, i}$, where

$$
\begin{aligned}
& t_{D, i}^{j}=\left(\frac{\left(N_{C, i}\right)^{1 / 4} \cdot\left(N_{D, i}\right)^{1 / 4}}{\left(N_{C, i}\right)^{1 / 2} \cdot\left(t_{C, i}^{j}\right)^{1 / 4}}\right)^{4}, \\
& t_{D, i}^{j}=\frac{N_{D, i}}{N_{C, i} \cdot t_{C, i}^{j}} .
\end{aligned}
$$

\section{Conclusions}

Four factors, number of passengers, number of taxis, weather condition, and holiday period, significantly affect the decision of taxi drivers and the dispatching efficiency of the airport departure area. In the four factors, number of passengers and number of taxis have more influence on one single day's situation, while the weather condition and holiday period impacts much on the situation from one day to another day in a year. By calculating the product of passenger number and taxi number in the parking lot in the Chengdu Shuangliu Airport, the taxi drivers can generally determine the best choice that can obtain the maximum return. By using regression analysis to consider the weather condition and holiday period, the taxi drivers can have a rough idea of the passenger number in the airport in a specific day in a year so as to make rational decisions. Besides, the management department in the Shuangliu Airport can predict the traffic flow for one specific day in a 
year so that the dispatching efficiency can be improved by taking precaution actions.

To further improve the reliability and accuracy, the decision-making model for taxi drivers can combine the relevant reliable data to get the driver's optimal choice relatively quickly. The optimization model of dispatching efficiency can be combined with the system dynamics theory so as to cope with more complex queuing situations quickly and efficiently and obtain the most efficient dispatching efficiency.

\section{Data Availability}

Previously reported data were used to support this study and are available at http://youjia.chemcp.com/sichuan/chengdushi. html and http://www.cdtaxi.cn/ and http://www.cdairport. $\mathrm{com} /$.

\section{Conflicts of Interest}

The authors declare that there are no conflicts of interest regarding the publication of this paper.

\section{Authors' Contributions}

Y. Qian and S. Chen contribute equally to this paper.

\section{Acknowledgments}

This research was supported by the project of Anhui University of Finance and Economics: Research on the influence mechanism of social relations on the integration ability of the construction engineering innovation system and its ability improvement mechanism (project no. ACKYC20044) and Bengbu Social Science Planning Project: Research on the promotion mechanism and countermeasures of urban quality management ability: a case study of Bengbu City (project no. BB20B003).

\section{References}

[1] J. Shi and X. Ying, "Accessibility of a destination-based transportation system: a large airport study," Tsinghua Science and Technology, vol. 13, no. 2, pp. 211-219, 2008.

[2] Á. G. Marín, “Airport management: taxi planning," Annals of Operations Research, vol. 143, no. 1, pp. 191-202, 2006.

[3] Y. Li and Z. Zhang, "Technical methods of comprehensive transportation plans in the airport economic zone," Social and Behavioral Sciences, vol. 96, pp. 182-187, 2013.

[4] E. P. Gilbo, "Optimizing airport capacity utilization in air traffic flow management subject to constraints at arrival and departure fixes," IEEE Transactions on Control Systems Technology, vol. 5, no. 5, pp. 490-503, 1997.

[5] J. P. Cohen, "Some issues in benefit-cost analysis for airport development," Transportation Research Record: Journal of the Transportation Research Board, vol. 1567, no. 1, pp. 1-7, 1997.

[6] S. Damart and B. Roy, "The uses of cost-benefit analysis in public transportation decision-making in France," Transport Policy, vol. 16, no. 4, pp. 200-212, 2009.

[7] B. Cheng, L. Wang, J. Huang, X. Shi, X. Hu, and H. Chen, “A computing model for quantifying the value of structural health monitoring information in bridge engineering,"
Mathematical Problems in Engineering, vol. 2020, Article ID 8260909, 7 pages, 2020.

[8] P. Burgain, E. Feron, and J.-P. Clarke, "Collaborative virtual queue: benefit analysis of a collaborative decision making concept applied to congested airport departure operations," Air Traffic Control Quarterly, vol. 17, no. 2, pp. 195-222, 2009.

[9] J. Hu, J. Song, Y. Zhang, and Z. Yang, "Study on automatic creating method of public transportation dispatching form based on BP neural network," in Proceedings of the IEEE Conference on Intelligent Transportation Systems, pp. 863-867, Singapore, Singapore, September 2002.

[10] Y. Mo and Y. Su, "Neural networks based real-time transit passenger volume prediction," in Proceedings of the 2nd Conference on Power Electronics and Intelligent Transportation System, pp. 303-306, Shenzhen, China, December 2009.

[11] X. He, J. Chen, and H. Bian, "Application of BP neural network to forecast total traffic volume of waterway network," Shipping Management, vol. 28, no. 8, pp. 16-21, 2006, in Chinese.

[12] L. Yong and W. Tao, "The analysis of demand characteristics of passenger transportation based on BP neural network," Applied Mechanics and Materials, vol. 409-410, pp. 12921295, 2013.

[13] W. L. Zheng, J. W. Wang, and S. Q. Zhang, "Road transportation network planning and design based on the BP neural network," Advances in Transportation Studies, vol. 3, pp. 117-124, 2018.

[14] H. Liu, N. Xu, Z. Zhou, and J. Peng, "New HRRN in the bus arbitration of SoC design," in Proceedings of the 5th International Conference on ASIC, no. 1, pp. 405-408, Beijing, China, October 2003.

[15] P. S. Varma, "Design of modified HRRN scheduling algorithm for priority systems using hybrid priority scheme," Journal of Telematics \& Informatics, vol. 1, no. 1, pp. 14-19, 2013.

[16] B. Cheng, Y. Wei, W. Zhang et al., "Evolutionary game simulation on government incentive strategies of prefabricated construction: a system dynamics approach," Complexity, vol. 2020, Article ID 8861146, 11 pages, 2020.

[17] H. Chen, H. Li, Y. Wang, and B. Cheng, "A comprehensive assessment approach for water-soil environmental risk during railway construction in ecological fragile region based on AHP and MEA," Sustainability, vol. 12, no. 19, p. 7910, 2020.

[18] T. Günther, M. Hildebrandt, H. Fricke, and M. Strasser, "Contributions of advanced taxi time calculation to airport operations efficiency," Journal of Aerospace Operations, vol. 1, no. 3, pp. 321-346, 2011.

[19] V. H. L. Cheng, V. Sharma, and D. C. Foyle, "A study of aircraft taxi performance for enhancing airport surface traffic control," IEEE Transactions on Intelligent Transportation Systems, vol. 2, no. 2, pp. 39-54, 2001.

[20] Y. Hai, W. Y. L. Cowina, S. C. Wong, and G. H. B. Michael, "Equilibria of bilateral taxi-customer searching and meeting on networks," Transportation Research, Part B, vol. 44, no. 8-9, pp. 1067-1083, 2010.

[21] H. Lee, I. Simaiakis, and H. Balakrishnan, "A comparison of aircraft trajectory-based and aggregate queue-based control of airport taxi processes," in Proceedings of the 29th Digital Avionics Systems Conference, IEEE, Salt Lake City, UT, USA, October 2010.

[22] P. Balakrishna, R. Ganesan, and L. Sherry, “Airport taxi-out prediction using approximate dynamic programming: intelligence-based paradigm," Transportation Research Record: 
Journal of the Transportation Research Board, vol. 2052, no. 1, pp. 54-61, 2008.

[23] L. Jian, L. Xiao, and F. Quan, "Optimal scheduling model for hub airport taxi based on improved ant colony collaborative algorithm," Journal of Computer Applications, vol. 30, no. 4, pp. 1000-1003, 2010.

[24] Oil Price", Last Modified September 14, 2019, http://youjia. chemcp.com/sichuan/chengdushi.html.

[25] Chengdu Taxi”, Last Modified September 14, 2019, http:// www.cdtaxi.cn/.

[26] C. Liu and K. Guo, "Airport taxi scheduling optimization based on genetic algorithm," in Proceedings of the 2010 International Conference on Computational Intelligence and Security, pp. 205-208, Nanning, China, December 2010.

[27] Chengdu Shuangliu International Airport", Last Modified September 14, 2019, http://cdairport.com/.

[28] H.-J. Roh, S. Datla, and S. Sharma, "Effect of snow, temperature and their interaction on highway truck traffic," Journal of Transportation Technologies, vol. 3, no. 1, pp. 24-38, 2013. 